\title{
Effect of ruminal administration of soy sauce oil on rumen fermentation, milk production and blood parameters in dairy cows
}

\author{
Daiji Konno ${ }^{1,2}$, Masanobu Takahashi', Ikuo Osaka², Takenori Orihashi', Kiyotaka Sakai', \\ Kenji Sera ${ }^{3}$, Yoshiaki Obara ${ }^{3}$, and Yasuo Kobayashi ${ }^{1, *}$
}

\author{
* Corresponding Author: Yasuo Kobayashi \\ Tel: +81-011-706-2476, Fax: +81-011-706-2476, \\ E-mail: kyas@anim.agr.hokudai.ac.jp \\ ${ }^{1}$ Graduate School of Agriculture, Hokkaido University, \\ Sapporo, Hokkaido 0608589, Japan \\ 2 Dairy Research Center, Hokkaido Research \\ Organization, Nakashibetsu, Hokkaido 086-1135, \\ Japan \\ ${ }^{3}$ Mito Research Center, Meiji Feed CO., LTD., Ibaraki, \\ Ibaraki, 311-3123, Japan \\ ORCID \\ Daiji Konno \\ https://orcid.org/0000-0001-5895-5000 \\ Masanobu Takahashi \\ https://orcid.org/0000-0003-0496-3237 \\ Ikuo Osaka \\ https://orcid.org/0000-0001-5681-3498 \\ Takenori Orihashi \\ https://orcid.org/0000-0002-8007-4856 \\ Kiyotaka Sakai \\ https://orcid.org/0000-0003-4309-9680 \\ Kenji Sera \\ https://orcid.org/0000-0001-9493-0580 \\ Yoshiaki Obara \\ https://orcid.org/0000-0002-5866-8420 \\ Yasuo Kobayashi \\ https://orcid.org/0000-0003-2001-8884
}

Submitted Jul 31, 2019; Revised Oct 14, 2019; Accepted Nov 19, 2019
Objective: To evaluate soy sauce oil (a by-product of making whole soybean soy sauce) as a new dietary lipid source, a large amount of soy sauce oil was administered into the rumen of dairy cows.

Methods: Four Holstein dairy cows fitted with rumen cannulae were used in a 56-day experiment. Ruminal administration of soy sauce oil $(1 \mathrm{~kg} / \mathrm{d})$ was carried out for 42 days from day 8 to day 49 to monitor nutritional, physiological and production responses.

Results: Dry matter intake and milk yield were not affected by soy sauce oil administration, whereas $4 \%$ fat-corrected milk yield and the percentage of milk fat decreased. Although ruminal concentration of total volatile fatty acids (VFA) and the proportion of individual VFA were partially affected by administration of soy sauce oil, values were within normal ranges, showing no apparent inhibition in rumen fermentation. Administration of soy sauce oil decreased the proportions of milk fatty acids with a carbon chain length of less than 18, and increased the proportions of stearic, oleic, vaccenic and conjugated linoleic acids. Conjugated linoleic acid content in milk became 5.9 to 8.8 times higher with soy sauce oil administration. Blood serum concentrations of non-esterified fatty acid, 3-hydroxybutyric acid, total cholesterol, free cholesterol, esterified cholesterol, triglyceride and phospholipid increased with administration of soy sauce oil, suggesting a higher energy status of the experimental cows. Conclusion: The results suggest that soy sauce oil could be a useful supplement to potentially improve milk functionality without adverse effects on ruminal fermentation and animal health. More detailed analysis is necessary to optimize the supplementation level of this new lipid source in feeding trials.

Keywords: Dairy Cow; Fatty Acid; Milk; Rumen Fermentation; Soy Sauce Oil

\section{INTRODUCTION}

Conjugated linolenic acid (CLA), mainly cis-9 trans-11 CLA, has been extensively studied since the 1990s due to its anti-carcinogenic and anti-atherogenic functions [1,2], which can lead to positive effects on human health if adequately consumed. CLA is relatively abundant in food of ruminant origin [3] because it is generated within ruminant tissues such as the rumen and mammary gland. CLA is derived from linoleic acid via rumen microbial hydrogenation [4]. This can be outflowed from the rumen, absorbed in the lower tract and finally transferred into milk [5]. Also, CLA is derived from trans-11-octadecenoic acid (vaccenic acid), one of the further hydrogenated intermediates that can be converted to CLA in mammary gland [6]. As CLA in milk is primarily originated from dietary linoleic acid and its metabolites, the supply of such fatty acids is a key issue for production of milk 
with a higher proportion of CLA. It has been reported that CLA content in milk can be increased by feeding extruded soybean [7], roasted soybean [8] and pasturage [9], all of which are sources of linoleic acid. In the meantime, feeding oil often decreases feed intake by affecting rumen fermentation to lower fiber digestibility, intestinal hormones and hepatic fat oxidation [10-12]. In addition, milk fat decreases as the feeding amount of free or esterified fatty acid increases; therefore, dietary ether extract (EE) should be lower than $6 \%$ to $7 \%$ [13]. Thus, selection of lipid source and supplementation level are important.

Soy sauce oil, a by-product of making whole soybean soy sauce, is obtained by squeezing and separating a mash that has undergone a brewing process with yeast and lactic acid bacterium using whole soybeans, wheat and salt as raw materials. It might be expected that the CLA content of milk can be increased by feeding soy sauce oil to dairy cows since soy sauce oil is as rich in linoleic acid as soybean oil is. However, most soy sauce oil is currently used as a fuel alternative to heavy oil. If soy sauce oil is usable as a dietary lipid source for dairy cows, the application would be useful in terms of promotion of resource recycling, feed self-sufficiency rate and reduction of feed costs.

Preliminary evaluation of soy sauce oil as a dietary lipid for ruminants was carried out by Shibata et al [14]. They indicated that soy sauce oil has no negative effect on dry matter (DM) intake, milk yield and composition, while the proportion of CLA in milk fat increased with ruminal administration of soy sauce oil at $0.4 \mathrm{~kg} / \mathrm{d}$. Although that report pointed out the usefulness of soy sauce oil for dairy cows, the study was short ( 2 weeks) and provided limited information on the potential of this new lipid substrate. New feed materials, especially lipid substrates, should be evaluated in relation to feed intake since excess supply of dietary lipid can suppress DM intake, which can hamper livestock production performance. Therefore, responses to feed intake of soy sauce oil should also be assessed, especially to determine the upper limit of its supplementation.

The purpose of the present study was to clarify the effects of a large amount $(1 \mathrm{~kg} / \mathrm{d})$ of soy sauce oil administration on feed intake, ruminal fermentation, blood parameters and dairy performance (milk production and composition) of cows over a long-term period. The soy sauce level of $1 \mathrm{~kg} / \mathrm{d}$ was defined to temporarily set EE content of total feed at $10 \%$. Our hypothesis was that this new lipid source is useful for improving milk quality in terms of functional fatty acid content without negatively affecting rumen fermentation and animal health. Although the amount of soy sauce oil administered is obviously not practical, to the best of our knowledge, this study is the first detailed evaluation of soy sauce oil with respect to what can be expected from this new lipid source.

\section{MATERIALS AND METHODS}

\section{Animals and diets}

All the research protocols regarding animal care followed the Guidelines for Animal Experimentation of the local independent administrative agency of the Hokkaido Research Organization.

Four primiparous Holstein dairy cows $(587 \pm 93 \mathrm{~kg}$ body weight with $213 \pm 23$ days in milk), fitted with 10 -cm (internal diameter) soft plastic cannulae (Bar Diamond Inc., Parma, ID, USA), were used in a 56-day feeding experiment. They were fed a total mixed ration (TMR) consisting of $75.4 \%$ grass silage, $13.7 \%$ corn, $9.9 \%$ soybean meal, $0.7 \%$ calcium carbonate and $0.3 \%$ di-calcium phosphate on a DM basis (Table 1). For the adjustment of diet formulation, DM content of grass silage was determined weekly. TMR was given once daily (10.00 h) ad libitum, which was equivalent to $110 \%$ of the expected intake. Then, the amounts of diet offered and refused were recorded daily. Cows were housed in tie stalls with rubber mats bedded with sawdust. Fresh water was available at all times. Cows were milked twice daily (09:00 and 19:00) and milk production was recorded at each milking. Cows were weighed weekly during the feeding experiment.

For the treatment, soy sauce oil (Meiji Feed Co. Ltd., Tokyo, Japan) was directly administered via cannula into the rumen of each cow at a level of $1 \mathrm{~kg} / \mathrm{d}$ during the period from day 8 to day 49 . EE content in the total feed was about $10 \%$. Soy sauce oil was administered twice daily (08:30 and 17:30) by equally dividing the daily allowance. Thus, the morning administration of oil was $1.5 \mathrm{~h}$ before TMR feeding. Soy sauce oil was not administered for the first 7 days and the last 7 days of the feeding experiment, which were regarded as pre- and post-administration periods.

Table 1. Formulation and chemical composition of the experimental total mixed ration

\begin{tabular}{ll}
\hline Items & $\%$ \\
\hline Ingredients (\% dry matter) & 75.4 \\
$\quad$ Grass silage & 13.7 \\
Corn & 9.9 \\
Soybean meal & 0.7 \\
Calcium carbonate & 0.3 \\
Dicalcium phosphate & \\
Chemical composition (\% dry matter) & 17.3 \\
Crude protein & 3.4 \\
Ether extract & 47.3 \\
Neutral detergent fiber & 22.5 \\
Non fiber carnohydrate & 1 ) \\
Total digestible nutrients & 64.5 \\
\hline 1) Organic matter = (crude protein + ether extract + neutral detergent fiber).
\end{tabular}




\section{Sample collection}

Milk was sampled on days 2, 5, 8 to $28,30,37,44,51$, and 54 and divided into plastic vials for storage at $-30^{\circ} \mathrm{C}$ for longchain fatty acid analysis. Rumen and blood samples were obtained via the ruminal cannula and tail vein, respectively, at $08: 00$ on days $5,6,8,9,11,13,16,19,23,26,30,37,44$, 51 , and 54. In addition, on day 39 (week 6), rumen samples were taken at $-0.5,0,0.5,1,2,3,4,5,6,7,8$, and $9 \mathrm{~h}$ after the morning administration of soy sauce oil to determine diurnal changes in fermentation parameters.

Rumen sampling was done from the dorsal and ventral sacs of the rumen by hand, and rumen contents were mixed and then strained through four layers of surgical gauze to collect representative filtrate in a plastic vial. The $\mathrm{pH}$ of the filtrate was measured using an electrode (HM-50G, TOA-DKK, Tokyo, Japan), and then stored $-30^{\circ} \mathrm{C}$ for further analysis. Blood samples were centrifuged to obtain serum, and stored at $-30^{\circ} \mathrm{C}$ until analysis.

Feed samples including grass silage, corn and soybean meal were collected weekly and dried in a $60^{\circ} \mathrm{C}$ forced-air oven for $48 \mathrm{~h}$ for DM determination. The dried feed samples were ground and sieved through a 1-mm screen using a cutting mill and used for chemical analysis.

\section{Chemical and statistical analysis}

Feed samples were analyzed for DM, crude protein (CP), EE, and neutral detergent fiber following standard procedures [15]. Milk samples were employed for the analysis of fat, protein, and lactose by infrared analysis (Milko-Scan FT120; Foss Electric, Hillerod, Denmark).

Frozen samples of rumen, milk and blood serum were thawed at $4^{\circ} \mathrm{C}$ and employed for the following analyses. Ammonia nitrogen was analyzed using the phenol hypochlorite method [16]. Volatile fatty acid (VFA) was analyzed a gas chromatograph (GC-14B; Shimadzu Co., Kyoto, Japan) using crotonic acid as an internal standard [17]. Fatty acid analysis was performed after conversion of fatty acids into fatty acid methyl esters (FAME), which were analyzed according to the method of Aii et al [18] with minor modifications. Briefly, after milk fat was extracted by hexane, FAME was prepared by the trans-methylation procedure according to Christie's method [19]. Methyl esterified samples were analyzed using a gas chromatograph (GC-14B; Shimadzu Co., Japan) fitted with a flame ionization detector, using a silica capillary column (SP-2560, $100 \mathrm{~m} \times 0.25 \mathrm{~mm}$ (i.d.) with $0.20 \mu \mathrm{m}$ film thickness; Spelco, Bellefonte, PA, USA). Biochemical analysis of blood serum was conducted using an automatic biochemical analyzer (SYNCHRON CX5, Beckman Coulter, Inc., Brea, CA, USA).

Data were averaged and are shown as representative values of each week (i.e. data shown for week 1 through week 8 are averages from all samples taken in the corresponding week). All the data were analyzed using JMP (SAS Institute Inc., Cary, NC, USA) as a paired t-test. A level of $\mathrm{p}<0.05$ was defined as significant.

\section{RESULTS}

Table 2 shows nutrient intake during the experimental period with or without soy sauce oil administration into the rumen. Total DM intake was not affected by soy sauce oil administration, and ranged from 12.9 to $14.0 \mathrm{~kg} / \mathrm{d}$. With administration of soy sauce oil, proportions of EE intake and total digestible nutrients intake in total DM intake increased, while the proportions of grass silage and $\mathrm{CP}$ intake in total DM intake decreased.

Milk yield and composition are shown in Table 3. Milk yield was unaffected by soy sauce oil administration, and ranged from 19.3 to $20.8 \mathrm{~kg} / \mathrm{d}$. However, fat-corrected milk yield and milk fat percentage decreased with soy sauce oil administration, and these persisted even after cessation of oil administration at week 8. Protein, lactose and solid-notfat contents were not affected by ruminal administration of soy sauce oil.

Weekly changes of ruminal fermentation parameters including $\mathrm{pH}$, ammonia $\mathrm{N}$, and VFA in cows ruminally administered soy sauce oil are indicated in Table 4. Ruminal $\mathrm{pH}$ and concentration of ammonia were not affected by soy sauce oil.

Table 2. Effect of ruminal administration of soy sauce oil on nutrient intake in dairy cows

\begin{tabular}{|c|c|c|c|c|c|c|c|c|c|}
\hline \multirow{2}{*}{ Items } & \multicolumn{8}{|c|}{ Week of experiment ${ }^{1)}$} & \multirow{2}{*}{ SE } \\
\hline & 1 & 2 & 3 & 4 & 5 & 6 & 7 & 8 & \\
\hline Dry matter intake $(\mathrm{kg})$ & 13.9 & 14.0 & 12.9 & 13.0 & 13.9 & 14.0 & 13.7 & 13.6 & 0.21 \\
\hline Grass silage (dry matter intake, \%) & 75.4 & $70.0^{*}$ & $69.5^{*}$ & $69.5^{*}$ & $69.9^{*}$ & $70.0^{*}$ & $69.9^{*}$ & 75.4 & 0.45 \\
\hline Ether extract (dry matter intake, \%) & 3.3 & $10.2^{*}$ & $10.8^{*}$ & $11.0^{*}$ & $10.6^{*}$ & $10.4^{*}$ & $10.6^{*}$ & 3.5 & 0.57 \\
\hline Crude protein (dry matter intake, \%) & 17.0 & $15.8^{*}$ & $15.7^{*}$ & $15.9^{*}$ & $16.4^{*}$ & $16.4^{*}$ & $16.4^{*}$ & 17.7 & 0.11 \\
\hline Total digestible nutrient (dry matter intake, \%) & 64.5 & $75.0^{*}$ & $75.9^{*}$ & $75.8^{*}$ & $75.1^{*}$ & $75.0^{*}$ & $75.2^{*}$ & 64.5 & 0.87 \\
\hline
\end{tabular}

SE, pooled standard error.

1) Administration period of soy sauce oil is from 2 to 7 week.

* Significantly different from the value in 1 st week $(p<0.05)$. 
Table 3. Effect of ruminal administration of soy sauce oil on milk yield and composition in dairy cows

\begin{tabular}{|c|c|c|c|c|c|c|c|c|c|}
\hline \multirow{2}{*}{ Items } & \multicolumn{8}{|c|}{ Week of experiment ${ }^{1)}$} & \multirow{2}{*}{ SE } \\
\hline & 1 & 2 & 3 & 4 & 5 & 6 & 7 & 8 & \\
\hline Milk yield (kg/d) & 20.8 & 20.8 & 19.7 & 19.3 & 20.4 & 20.0 & 19.9 & 19.5 & 0.43 \\
\hline $4 \%$ fat corrected milk (kg/d) & 21.4 & 21.7 & $18.9^{*}$ & $17.3^{*}$ & $17.3^{*}$ & $16.9^{*}$ & $17.1^{*}$ & $17.2^{*}$ & 0.54 \\
\hline Fat $(\%)$ & 4.21 & 4.29 & $3.73^{*}$ & $3.31^{*}$ & $2.95^{*}$ & $2.97^{*}$ & $3.04^{*}$ & $3.22^{*}$ & 0.10 \\
\hline Protein (\%) & 3.23 & 3.12 & 3.12 & 3.08 & 2.99 & 3.00 & 2.98 & 3.00 & 0.04 \\
\hline Lactose (\%) & 4.31 & 4.34 & 4.30 & 4.28 & 4.27 & 4.31 & 4.33 & 4.33 & 0.02 \\
\hline Solid non fat (\%) & 8.46 & 8.45 & 8.43 & 8.36 & 8.23 & 8.28 & 8.30 & 8.31 & 0.05 \\
\hline
\end{tabular}

SE, pooled standard error.

1) Administration period of soy sauce oil is from 2 to 7 week.

* Significantly different from the value in 1 st week $(p<0.05)$.

Table 4. Effect of ruminal administration of soy sauce oil on ruminal pH, ammonia nitrogen concentration, total volatile fatty acid concentration, and proportions of acetic acid, propionic acid and n-butyric acid

\begin{tabular}{|c|c|c|c|c|c|c|c|c|c|}
\hline \multirow{2}{*}{ Items } & \multicolumn{8}{|c|}{ Week of experiment ${ }^{1)}$} & \multirow{2}{*}{ SE } \\
\hline & 1 & 2 & 3 & 4 & 5 & 6 & 7 & 8 & \\
\hline $\mathrm{pH}$ & 6.5 & 6.5 & 6.5 & 6.6 & 6.6 & 6.5 & 6.5 & 6.7 & 0.03 \\
\hline Ammonia-N (mg/dL) & 7.8 & 7.7 & 8.2 & 6.7 & 9.0 & 9.6 & 12.2 & 8.6 & 0.46 \\
\hline Total VFA (mmol/dL) & 9.8 & 9.3 & 10.9 & $8.1^{*}$ & 7.6 & 10.5 & 10.3 & $8.3^{*}$ & 0.28 \\
\hline Acetic acid (mol \%) & 69.2 & 67.8 & 65.5 & 68.0 & 70.6 & 68.1 & 67.4 & $71.0^{*}$ & 0.37 \\
\hline Propionic acid (mol \%) & 16.6 & 17.5 & 18.6 & $18.2^{*}$ & 18.1 & 18.2 & $18.9^{*}$ & 15.7 & 0.25 \\
\hline n-Butyric acid (mol \%) & 11.4 & 11.4 & 12.5 & 10.9 & $8.2^{*}$ & 10.4 & $10.2^{*}$ & 10.4 & 0.31 \\
\hline
\end{tabular}

SE, pooled standard error; VFA, volatile fatty acid.

1) Administration period of soy sauce oil is from 2 to 7 week.

* Significantly different from the value in 1 st week $(p<0.05)$.

Although ruminal concentration of total VFA and proportions of acetate, propionate and butyrate were partially affected by soy sauce oil, the values were within normal ranges, showing no marked inhibition in rumen fermentation.

Diurnal changes of ruminal fermentation parameters on day 39 (week 6) in cows ruminally administered soy sauce oil are shown in Table 5. At $3 \mathrm{~h}$ after feeding and later (and at $1.5 \mathrm{~h}$ after administration of soy sauce oil and later), ruminal $\mathrm{pH}$ decreased and ammonia level increased. However, concentration of total VFA, molar proportions of acetate, pro- pionate and butyrate were relatively stable.

Table 6 shows fatty acid composition and cis-9 trans- 11 CLA content of milk. With administration of soy sauce oil, proportions of butyric (C4:0), caproic (C6:0), caprylic (C8:0), capric (C10:0), lauric (C12:0), myristic (C14:0), palmitic (C16:0), and margaric (C17:0) acids decreased, while those of stearic (C18:0), oleic (C18:1), trans-11 C18:1 (vaccenic) acids and cis-9 trans-11 CLA increased (Table 6). Other isomers such as cis-10 trans-12 CLA and trans- 9 cis-11 CLA were not detected (CLA means cis-9 trans-11 CLA hereafter,

Table 5. Effect of ruminal administration of soy sauce oil on diurnal changes in ruminal pH, total volatile fatty acid concentration, and proportions of acetic acid, propionic acid and n-butyric acid

\begin{tabular}{|c|c|c|c|c|c|c|c|c|c|c|c|c|c|}
\hline \multirow{2}{*}{ Items } & \multicolumn{12}{|c|}{ Hours after administration of soy sauce oil ${ }^{1)}$} & \multirow{2}{*}{ SE } \\
\hline & -0.5 & 0 & 0.5 & 1 & 2 & 3 & 4 & 5 & 6 & 7 & 8 & 9 & \\
\hline pH & 6.7 & 6.6 & 6.6 & 6.6 & 6.4 & $6.1^{*}$ & $6.3^{*}$ & $6.2^{*}$ & $6.1^{*}$ & $6.2^{*}$ & $6.2^{*}$ & $6.2^{*}$ & 0.03 \\
\hline Ammonia-N (mg/dL) & 7.9 & 9.6 & 10.0 & 8.7 & 14.4 & $20.2^{*}$ & $15.0^{*}$ & $14.6^{*}$ & $15.6^{*}$ & 13.4 & 9.6 & 12.3 & 0.64 \\
\hline Total VFA (mmol/dL) & 8.5 & 8.8 & 8.8 & 8.4 & 10.0 & 11.1 & 10.2 & $10.2^{*}$ & $10.8^{*}$ & 10.7 & 10.0 & 10.3 & 0.20 \\
\hline Acetic acid (mol \%) & 68.2 & 67.5 & 67.1 & 67.4 & 66.2 & 66.0 & 67.6 & 67.8 & 66.8 & 67.3 & 68.0 & 66.5 & 0.17 \\
\hline Propionic acid (mol \%) & 17.4 & 17.9 & 18.0 & 17.8 & 18.8 & 18.4 & 16.9 & $16.3^{*}$ & 17.1 & 17.0 & 16.9 & 17.9 & 0.14 \\
\hline n-Butyric acid (mol \%) & 11.2 & 11.0 & 11.1 & 11.0 & 11.2 & 11.1 & 10.9 & 11.1 & 11.3 & 11.3 & 11.3 & 11.6 & 0.12 \\
\hline
\end{tabular}

SE, pooled standard error; VFA, volatile fatty acid.

1) TMR is fed at 1.5 hours after ruminal administration of soy sauce oil.

* Significantly different from the value before administration (average of values at -0.5 and 0 hours) $(p<0.05)$. 
Table 6. Effect of ruminal administration of soy sauce oil on milk fatty acid composition in dairy cows

\begin{tabular}{|c|c|c|c|c|c|c|c|c|c|}
\hline \multirow{2}{*}{ Items } & \multicolumn{8}{|c|}{ Week of experiment ${ }^{1)}$} & \multirow{2}{*}{ SE } \\
\hline & 1 & 2 & 3 & 4 & 5 & 6 & 7 & 8 & \\
\hline \multicolumn{10}{|l|}{ Fatty acid composition (\%) } \\
\hline C4:0 (butyric acid) & 4.1 & 4.3 & $3.6^{*}$ & 3.4 & 3.1 & $3.3^{*}$ & 3.4 & $3.6^{*}$ & 0.07 \\
\hline C6:0 (caproic acid) & 2.0 & $1.7^{\star}$ & $1.2^{*}$ & $1.1^{*}$ & $1.0^{*}$ & $1.0^{*}$ & $1.0^{*}$ & $1.4^{*}$ & 0.07 \\
\hline C8:0 (caprylic acid) & 1.1 & $0.8^{*}$ & $0.5^{*}$ & $0.4^{*}$ & $0.4^{*}$ & $0.4^{*}$ & $0.4^{*}$ & $0.6^{*}$ & 0.05 \\
\hline C0:0 (capric acid) & 2.3 & $1.6^{*}$ & $0.9^{*}$ & $0.8^{*}$ & $0.7^{*}$ & $0.7^{*}$ & $0.7^{*}$ & $1.2^{*}$ & 0.10 \\
\hline C12:0 (lauric acid) & 2.7 & $1.9^{*}$ & $1.1^{*}$ & $1.1^{*}$ & $1.0^{*}$ & $1.1^{*}$ & $1.0^{*}$ & $1.6^{*}$ & 0.11 \\
\hline C14:0 (myristic acid) & 11.1 & $8.1^{*}$ & $5.7^{*}$ & $5.6^{*}$ & $5.7^{*}$ & $6.1^{*}$ & $5.7^{*}$ & 8.6 & 0.00 \\
\hline C14:1 (myristoleic acid) & 0.9 & $0.7^{*}$ & $0.4^{*}$ & $0.5^{*}$ & 0.6 & 0.6 & 0.5 & 0.9 & 0.04 \\
\hline C15:0 (pentadecylic acid) & 1.2 & 1.0 & $0.9^{*}$ & $0.9^{*}$ & 1.0 & 1.1 & 1.0 & 1.2 & 0.02 \\
\hline C16:0 (palmitic acid) & 33.0 & $25.9^{*}$ & $20.7^{*}$ & $20.9^{*}$ & $22.3^{*}$ & $21.7^{*}$ & $21.0^{*}$ & $26.6^{*}$ & 0.80 \\
\hline C16:1 (palmitoleic acid) & 1.7 & $1.5^{*}$ & 1.6 & $1.9^{*}$ & $2.1^{*}$ & 1.8 & 1.9 & 1.9 & 0.04 \\
\hline C17:0 (margaric acid) & 0.8 & $0.5^{*}$ & $0.4^{*}$ & $0.4^{*}$ & $0.4^{*}$ & $0.4^{*}$ & $0.4^{*}$ & $0.5^{*}$ & 0.03 \\
\hline C18:0 (stearic acid) & 9.7 & 11.1 & $12.8^{*}$ & $11.1^{*}$ & 10.2 & 10.6 & 10.5 & 9.5 & 0.28 \\
\hline C18:1 (oleic acid) & 20.9 & 21.2 & $25.0^{*}$ & $25.4^{*}$ & 24.2 & $25.4^{*}$ & $25.7^{*}$ & $26.2^{*}$ & 0.45 \\
\hline trans-11 C18:1 (trans-vaccenic acid) & 1.4 & $9.9^{*}$ & $14.4^{*}$ & $14.7^{*}$ & $14.2^{*}$ & $13.3^{*}$ & $13.5^{*}$ & $5.4^{*}$ & 0.91 \\
\hline C18:2 (linoleic acid) & 1.4 & 1.4 & 1.3 & 1.4 & 1.5 & 1.8 & 1.8 & $1.7^{*}$ & 0.06 \\
\hline cis-9 trans-11 CLA (conjugated linoleic acid) & 0.6 & $3.4^{*}$ & $5.4^{*}$ & $6.3^{*}$ & $7.2^{*}$ & $6.1^{*}$ & $6.5^{*}$ & $3.1^{*}$ & 0.40 \\
\hline C18:3 (linolenic acid) & 0.6 & $0.4^{*}$ & $0.3^{*}$ & $0.3^{*}$ & $0.4^{*}$ & 0.5 & 0.5 & $0.4^{*}$ & 0.02 \\
\hline Others (unidentified) & 4.5 & 4.6 & $3.8^{*}$ & 3.8 & 4.0 & 4.1 & 4.5 & $5.6^{*}$ & 0.15 \\
\hline cis-9 trans-11 CLA content (mg/milk $100 \mathrm{~g})$ & 24.2 & $143.6^{*}$ & $200.0^{*}$ & $207.0^{*}$ & $212.3^{*}$ & $182.0 *$ & $198.4^{*}$ & $98.5^{*}$ & 11.97 \\
\hline
\end{tabular}

SE, pooled standard error.

${ }^{1)}$ Administration period of soy sauce oil is from 2 to 7 week.

* Significantly different from the value in 1 st week $(p<0.05)$.

unless stated otherwise). Increased proportions of vaccenic acid and CLA were consistent throughout soy sauce oil administration (weeks 2 to 7 ) and even after cessation of administration (week 8). CLA content in milk was elevated by soy sauce oil up to $212.3 \mathrm{mg} / 100 \mathrm{~g}$ of milk at week 5 of the experimental period.

Blood parameters are given in Table 7. Concentrations of non-esterified fatty acid (NEFA), 3-hydroxybutyric acid, total cholesterol, free cholesterol, esterified cholesterol, triglyceride, and phospholipid increased with administration of soy sauce oil, while those of glucose, aspartate aminotransferase, $\gamma$-glutamyl transpeptidase, inorganic phosphorus and magnesium were unaffected. Concentrations of blood urea nitrogen, total protein, cholesterol ester ratio and calcium showed stable values throughout the experimental period.

\section{DISCUSSION}

The present study aimed to evaluate the influence of administration of a large amount of soy sauce oil on the nutrition and physiology of dairy cows, especially rumen fermentation. Although feeding dairy cows a high proportion of lipids causes a decrease in DM intake, it has little influence on ruminal fermentation [20]. The administration of soy sauce oil in the present study did not negatively influence feed intake (Table 2 ), even though EE proportion in the diet exceeded the recommended value ( $6 \%$ to $7 \%$ ) [13]. The present results with no depressed feed intake, even with a diet having $10.2 \%$ to $11.0 \% \mathrm{EE}$, suggest that soy sauce oil could be an alternative lipid energy source in the ruminant diet.

Ruminal $\mathrm{pH}$ in the present study was within the optimal range (6.1 to 6.7) to ensure normal growth of major rumen microbes [21], and other ruminal parameters including ammonia and VFA were not greatly affected by the administration of $1 \mathrm{~kg}$ of soy sauce oil (Table 4). However, Shibata et al [14] reported that rumen fermentation was slightly inhibited by soy sauce oil at a lower level of administration $(0.4 \mathrm{~kg} / \mathrm{d})$, as was observed for decreased VFA concentration. The reason for the different responses between the two studies is not clear, although the response in feed intake should be examined not by direct ruminal administration, but by a feeing study, and allowable supplementation levels should be proposed for the application of soy sauce oil. According to diurnal changes in rumen parameters at 6 weeks (fully adapted to soy sauce oil), administration of soy sauce oil did not seem to lead to abrupt changes in rumen fermentation (Table 5).

Generally, the decrease in milk fat can be mainly explained by the decrease of acetate production in the rumen [22] caused by lowered dietary proportion of roughage. Milk fat percentage 
Table 7. Effect of ruminal administration of soy sauce oil on blood parameters in dairy cows

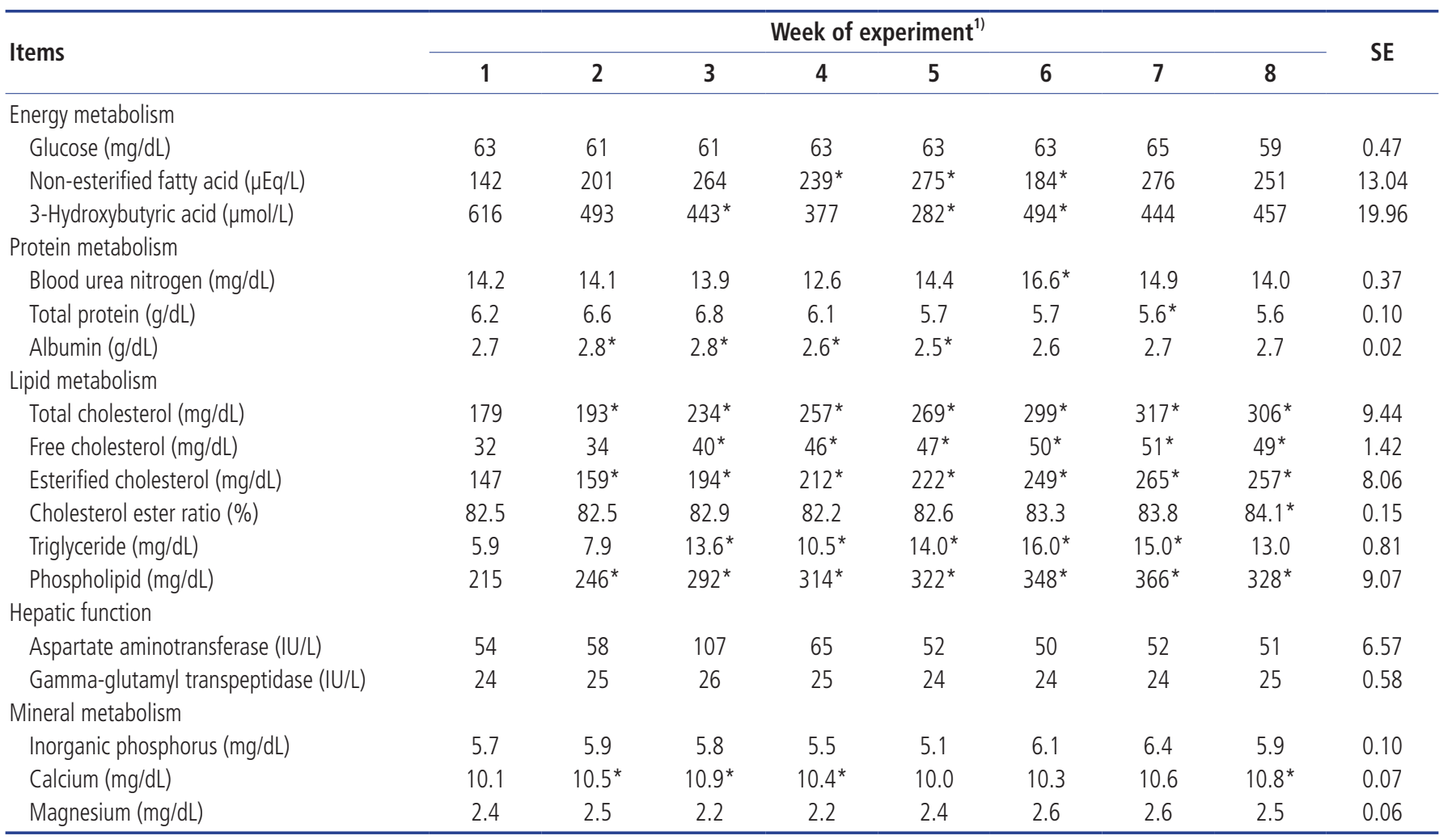

SE, pooled standard error.

1) Administration period of soy sauce oil is from 2 to 7 week.

* Significantly different from the value in 1 st week $(p<0.05)$.

was markedly decreased with soy sauce oil administration in the present study (Table 3) regardless of no apparent inhibition of ruminal acetate level (Table 4). Therefore, it is thought that the decreased milk fat is attributable to the bio-hydrogenation theory, as described below.

The bio-hydrogenation theory [23] is supported by the fact that particular intermediates via ruminal hydrogenation of linoleic acid are absorbed in the lower tract and inhibit milk fat synthesis in the mammary gland [23]. The trans-10 cis-10 CLA is one of such intermediates to inhibit milk fat synthesis [24]. In fact, milk fat yield decreases as the proportion of this CLA increases [25]. In addition, it has been indicated that cis-10 trans-12 CLA [26] and trans-9 cis-11 CLA [27] also inhibit milk fat synthesis. Soy sauce oil used in the present study is rich in C18 unsaturated fatty acids (83\%) that can be converted to the above fatty acids to negatively influence milk fat synthesis in the mammary gland. This is a possible explanation for the milk fat decrease in the present study. However, all these possibilities are to be confirmed by biopsy experiments of liver, adipose tissue and mammary gland.

Feeding with a diet rich in polyunsaturated fatty acids as substrates for ruminal synthesis of vaccenic acid and CLA is a useful way to enhance the CLA content of milk. There have been reports that the CLA content of milk is doubled with feeding lactating dairy cows a diet containing $5 \%$ soybean oil [28], and more than doubled (2.3 times) by grazing in comparison with feeding TMR [9]. In this experiment using cows administered soy sauce oil rich in linoleic acid, the CLA proportion in milk fat and CLA content of milk increased 12.0- and 8.8-fold at maximum, respectively (Table 6). Such enrichment of CLA in milk is much higher than the values reported to date.

The NEFA, 3-hydroxybutyric acid (THB), cholesterol, triglyceride and phospholipid contents in blood serum were increased by ruminal administration of soy sauce oil (Table 7), as was observed for other oil/fat administration [29-31]. The increased blood lipids could be caused by soy sauce oil administration, but not by body fat mobilization because the body weight of experimental cows did not decrease in the present study (body weight ranged from 582 to $597 \mathrm{~kg}$ ). These values did not return to the original (pre-treatment) level at 1 week after cessation of administration, as was observed for milk fat percentage and milk fatty acid profiles (Tables 3, 7), indicating a residual effect of soy sauce oil administration. Other blood parameters concerning hepatic function and mineral metabolism were fairly stable within normal levels throughout the experimental period. Therefore, it is thought 
that soy sauce oil does not adversely influence the health of dairy cows.

Although the present study represents the first detailed evaluation of the utilization of soy sauce oil as a new lipid source and further study is needed, we revealed that administration of soy sauce oil to dairy cows has the potential to increase the CLA content of milk. However, soy sauce oil could also reduce milk fat percentage, possibly due to absorption of hydrogenated fatty acid intermediates to inhibit milk fat synthesis. Obviously, the adequate dose level of soy sauce oil should be experimentally clarified not by direct ruminal administration as in the present study, but by more practical feeding studies.

\section{CONFLICT OF INTEREST}

We certify that there is no conflict of interest with any financial organization regarding the material discussed in the manuscript. Orihashi T, Sakai K, Sera K, Obara Y are employees of Mito Research Center, Meiji Feed CO., LTD..

\section{ACKNOWLEDGMENTS}

The authors would like to express their gratitude towards the staff of the dairy cattle group, Dairy Research Center, Hokkaido Research Organization, who were involved in animal management, feeding, and other support for this study.

\section{REFERENCES}

1. Parodi PW. Cows' milk fat components as potential anticarcinogenic agents. J Nutr 1997;127:1055-60. https://doi.org/ 10.1093/jn/127.6.1055

2. Chilliard Y, Ferlay A, Doreau M. Effect of different types of forages, animal fat or marine oils in cow's diet on milk fat secretion and composition, especially conjugated linoleic acid (CLA) and polyunsaturated fatty acids. Livest Prod Sci 2001; 70:31-48. https://doi.org/10.1016/S0301-6226(01)00196-8

3. O'Shea M, Lawless F, Stanton C, Devery R. Conjugated linoleic acid in bovine milk fat: a food-based approach to cancer chemoprevention. Trends Food Sci Technol 1998;9:192-6. https://doi.org/10.1016/S0924-2244(98)00036-3

4. Jenkins TC. Lipid metabolism in the rumen. J Dairy Sci 1993; 76:3851-63. https://doi.org/10.3168/jds.S0022-0302(93)77727-9

5. Kepler CR, Tove SB. Biohydrogenation of unsaturated fatty acids. J Biol Chem 1967;242:5686-92.

6. Griinari JM, Corl BA, Lacy SH, Chouinard PY, Nurmela KVV, Bauman DE. Conjugated linoleic acid is synthesizes endogenously in lactating dairy cows by $\Delta^{9}$-desaturase. J Nutr 2000; 130:2285-91. https://doi.org/10.1093/jn/130.9.2285

7. Chouinard PY, Corneau L, Butler WR, Bauman DE, Chilliard Y, Drackley JK. Effect of dietary lipid source on conjugated linoleic acid concentrations in milk fat. J Dairy Sci 2001;84: 680-90. https://doi.org/10.3168/jds.S0022-0302(01)74522-5

8. Dhiman TR, Satter LD, Pariza MW, Galli MP, Albright K, Tolosa MX. Conjugated linoleic acid (CLA) content of milk from cows offered diets rich in linoleic and linolenic acid. J Dairy Sci 2000;83:1016-27. https://doi.org/10.3168/jds.S00220302(00)74966-6

9. Kelly ML, Kolver ES, Bauman DE, Van Amburgh ME, Muller LD. Effect of intake of pasture on concentrations of conjugated linoleic acid in milk of lactating cows. J Dairy Sci 1998;81: 1630-6. https://doi.org/10.3168/jds.S0022-0302(98)75730-3

10. Allen MS. Effects of diet on short-term regulation of feed intake by lactating dairy cattle. J Dairy Sci 2000;83:1598624. https://doi.org/10.3168/jds.S0022-0302(00)75030-2

11. Chalupa W, Rickabaugh B, Kronfeld DS, Sklan D. Rumen fermentation in vitro as influenced by long chain fatty acids. J Dairy Sci 1984;67:1439-44. https://doi.org/10.3168/jds. S0022-0302(84)81459-9

12. Palmquist DL, Jenkins TC. Fat in lactation rations. J Dairy Sci 1980;63:1-14. https://doi.org/10.3168/jds.S0022-0302 (80)82881-5

13. Subcommitee on Dairy Cattle Nutrition, National Research Council. Nutrient requirements of dairy cattle. 7th ed. Washington, DC, USA: National Academy Press; 2001.

14. Shibata H, Hashizume N, Gazi MR, et al. Effect of supplementation of soy sauce oil and Ca salts of fatty acids on rumen fermentation, milk production and conjugated linoleic acid in milk of dairy cows. Anim Sci J 2011;82:554-9. https://doi. org/10.1111/j.1740-0929.2011.00875.x

15. National Agriculture and Food Research Organization (NARO). Standard tables of feed composition in Japan (2009). Tokyo, Japan: Japan Livestock Industry Association; 2009.

16. Weatherburn MW. Phenol-hypochlorite reaction for determination of ammonia. Anal Chem 1967;39:971-4. https://doi. org/10.1021/ac60252a045

17. Suto T. The Clinical investigation of the bovine. Tokyo, Japan: Nosangyoson Bunka Kyokai; 1973.

18. Aii T, Takahashi S, Kurihara M, Kume S. Fatty acid composition of milk during a hot summer. Jpn J Zootech Sci 1988; 59:278-84. https://doi.org/10.2508/chikusan.59.278

19. Christie WW. A simple procedure for rapid transmethylation of glycerolipids and cholesteryl esters. J Lopid Res 1982;23: 1072-5.

20. Schauff DJ, Clark JH. Effects of feeding diets containing calcium salts of long-chain fatty acids to lactating dairy cows. J Dairy Sci 1992;75:2990-3002. https://doi.org/10.3168/jds.S00220302(92)78063-1

21. Obara Y. Foundation and application of ruminology. Tokyo, Japan: Rural Culture Association; 2006.

22. Woodford JA, Jorgensen NA, Barrington GP. Impact of dietary fiber and physical form on performance of lactating dairy cows. J Dairy Sci 1986;69:1035-47. https://doi.org/10.3168/ 
jds.S0022-0302(86)80499-4

23. Bauman DE, Griinari JM. Nutritional regulation of milk fat synthesis. Annu Rev Nutr 2003;23:203-27. https://doi.org/ 10.1146/annurev.nutr.23.011702.073408

24. Baumgard LH, Corl BA, Dwyer DA, Sæbø A, Bauman DE. Identification of the conjugated linoleic acid isomer that inhibits milk fat synthesis. Am J Physiol Regul Integr Comp Physiol 2000;278:R179-84. https://doi.org/10.1152/ajpregu. 2000.278.1.R179

25. de Veth MJ, Griinari JM, Pfeiffer AM, Bauman DE. Effect of CLA on milk synthesis in dairy cows: comparison of inhabitation by methyl esters and free fatty acids, and relationships among studies. Lipids 2004;39:365-72. https://doi.org/10. 1007/s11745-004-1240-4

26. Sæbø A, Sæbø PC, Griinari JM, Shingfield KJ. Effect of abomasal infusion of geometric isomers of 10, 12 conjugated linoleic acid on milk fat synthesis in dairy cows. Lipids 2005; 40:823-32. https://doi.org/10.1007/s11745-005-1444-7

27. Perfield II JW, Lock AL, Griinari JM, et al. Trans-9, cis-11 conjugated linoleic acid reduces milk fat synthesis in lactating dairy cows. J Dairy Sci 2007;90:2211-8. https://doi.org/10. 3168/jds.2006-745

28. Huang Y, Schoonmaker JP, Bradford BJ, Beitz DC. Response of milk fatty acid composition to dietary supplementation of soy oil, conjugated linoleic acid, or both. J Dairy Sci 2008; 91:260-70. https://doi.org/10.3168/jds.2007-0344

29. Moallem U, Katz M, Arieli A, Lehrer H. effects of peripartum propylene glycol or fats differing in fatty acid profiles on feed intake, production, and plasma metabolites in dairy cows. J Dairy Sci 2007;90:3846-56. https://doi.org/10.3168/jds.20070092

30. Loor JJ, Ferlay A Ollier A, Doreau M, Chilliard Y. Relationship among trans and conjugated fatty acids and bovine milk fat yield due to dietary concentrate and linseed oil. J Dairy Sci 2005;88:726-40. https://doi.org/10.3168/jds.S0022-0302 (05)72736-3

31. Viswanadha S, Giesy JG, Hanson TW, McGuire MA. Dose response of milk fat to intravenous administration of the trans-10, cis-12 isomer of conjugated linoleic acid. J Dairy Sci 2003;86:3229-36. https://doi.org/10.3168/jds.S0022-0302 (03)73926-5 